\title{
Catalytic synthesis of $\beta$-sitosterol linolenate by Pickering emulsion-immobilized lipase
}

\author{
Xinlong Liu, Lihui Wang*, Peng Liu, Na An, Guanghui Chen, Rui Zhao, and Zhongxia Hang \\ School of Biological Engineering, Tianjin Modern Vocational Technology College, Tianjin, 300350, China
}

\begin{abstract}
In order to promote the application of phytosterol ester, a new kind of catalyst was developed on the basis of traditional enzymatic synthesis method. Pickering emulsion catalyst (CRL@PE) with two-phase structure was constructed using isoctane and Candida rugosa lipase and employing nanotube as emulsifier. Then the CRL@PE was used to catalyze the synthesis of $\beta$-sitosterol linolenic acid ester with $\beta$-sitosterol and $\alpha$-linolenic acid as substrates. The effects of temperature, enzyme dosage, linolenic acid concentration and reaction time on the conversion rate of phytosterols were studied by single factor experiment and central composite design of response surface methodology. The optimal process parameters were obtained as follows: temperature of $29.45{ }^{\circ} \mathrm{C}$, lipase dossage of $10.97 \mathrm{U}$, linolenic acid concentration of 42.35 $\mathrm{mmol} / \mathrm{L}$, reaction time of $350.7 \mathrm{~min}$, and phytosterol conversion rate was $96.8 \pm 0.7 \%$ at these conditions. After reuse of CRL@PE for 10 times, the phytosterol conversion rate was $96.86 \%$, showing that the catalyst had good stability.
\end{abstract}

\section{Introduction}

Phytosterol can compete with cholesterol for binding sites in the metabolic process to inhibit cholesterol absorption, reducing the incidence of human cardiovascular diseases. It has been added to various foods as a cholesterol-reducing additive [1]. Among multitudinous sterols, $\beta$-sitosterol has superior efficacy, but it is difficult to be absorbed by the body due to the high-melting point and poor solubility in water [2]. The conversion of $\beta$-sitosterol to medium- or long-chain fatty acid ester can change the physical properties of $\beta$ sitosterol and allow it to be better incorporated into fatcontaining foods, increasing its bioavailability [3]. $\beta$ sitosterol linolenate is a good choice. It can not only promote the digestion and absorption of $\beta$-sitosterol, but also contain $\alpha$-linolenic acid with functions of reducing blood fat and protecting the liver.

The bio-enzymatic synthesis of $\beta$-sitosterol linolenate not only has mild reaction conditions, low energy consumption, few by-products, but also has no solvent contamination [4]. However, the free enzyme has a high price and poor stability and is difficult to separate from the substrate, which limits its application and dissemination. Enzyme immobilization technology can effectively enhance the stability of the free enzyme and improve its application value in actual production. Zheng et al. immobilized CRL lipase on silica particles for the synthesis of phytosterol esters [5]. The maximum conversion rate of phytosterol was $95.3 \%$ under optimal conditions $(150 \mu \mathrm{mol} / \mathrm{mL}$ phytosterol, molar ratio of alcohol to acid of $1: 1.5$, at $55{ }^{\circ} \mathrm{C}$ for $24 \mathrm{~h}$ ). After repeated use of the immobilized enzyme for 7 times,
$78.6 \%$ of the initial activity were remained. In a biphasic solution constructed by Pickering emulsion with the utilization of solid particles as emulsifiers, the enzyme molecules can be immobilized in the aqueous phase. As an interfacial reaction enzyme, lipase spontaneously accumulates at the phase interface during the two reactions, thus showing an excellent catalytic activity [6]. In addition, the Pickering emulsion catalyst sinks into the bottom of the vessel only after standing for a little while, achieving separation from the reaction solution, and greatly simplifying the separation operation. Jiang et al. constructed the Pickering emulsion catalyst by using meso-porous silica-immobilized lipase as an emulsifier to catalyze and synthesize biodiesel with a maximum productivity of $95.8 \%$ (water content of $0.65 \%$, molar ratio of alcohol to oil of $2: 1,150 \mathrm{mg}$ enzyme, at $30{ }^{\circ} \mathrm{C}$ ) [7]. After repeatedly using the emulsion catalyst for 15 times, the productivity was $88.6 \%$. However, there is no report about Pickering emulsion-immobilized lipase for the catalytic synthesis of $\beta$-sitosterol linolenate.

\section{Materials and methods}

\subsection{Materials and reagents}

Multi-walled carbon nanotube (purity $>95$, Chengdu Institute Organic Chemistry, Chinese Academy of Sciences), Candida rugosa lipase (CRL, $15 \mathrm{U} / \mathrm{mg}$, Hangzhou Novocata Biotechnology Co., Ltd, China), fluorescein isothiocyanate (J\&K Scientific Ltd.), phytosterol ( $\beta$-sitosterol 73.96\%, brassicasterol 17\%, stigmasterol $5 \%$, campesterol $1 \%$, total sterol of $95.19 \%$,

\footnotetext{
* Corresponding author: wanglihui81@yeah.net (Lihui Wang)
} 
Xi'an Lantian Biological Engineering Co., Ltd.), and linolenic acid 80\% (Henan Linuo Biochemical Co., Ltd.).

\subsection{Instruments and equipment}

Ultrasonic cell pulverizer (BILON-250Y, Beijing Bilon Experimental Equipment Co., Ltd.) and gas chromatograph (SP-1000, Beijing Beifen-Ruili Analytical Instrument (Group) Co., Ltd.).

\subsection{Methods}

\subsubsection{Preparation of Pickering emulsion catalyst}

Multi-walled carbon nanotubes of $17 \mathrm{mg}$ were placed in a pressure bottle containing $3 \mathrm{~mL}$ isooctane, and sonication was performed for $1 \mathrm{~min}$ with an ultrasonic cell pulverizer (sonication of $1 \mathrm{~s}$ at a pause of $2 \mathrm{~s}$, at an ultrasonic temperature of $30 \mathrm{oC}$, and power of $18 \mathrm{w}$ ) to uniformly suspend the nanotubes in the isooctane. Phosphate buffered saline of $1 \mathrm{~mL}(\mathrm{pH} 7.0,0.1 \mathrm{~mol} / \mathrm{L})$ containing CRL lipase (9 U) were added, and sonication was performed for $5 \mathrm{~min}$. Then Pickering emulsion catalyst was obtained and named CRL@PE.

\subsubsection{Synthesis and detection of $\beta$-sitosterol linolenate}

Phytosterol of $30 \mu \mathrm{mol}(10 \mathrm{mmol} / \mathrm{L})$ were added in the pressure bottle containing CRL@PE, and the bottle was placed in a $55^{\circ} \mathrm{C}$ water bath kettle for $5 \mathrm{~min}$ to promote the dissolution of sterol. $\alpha$-linolenic acid $(10 \mathrm{mmol} / \mathrm{L})$ of $30 \mu \mathrm{mol}$ were added, and the mixture was put in a constant temperature shaking bath $(100 \mathrm{r} / \mathrm{min})$ at a certain temperature for $240 \mathrm{~min}$. The sample of $10 \mu \mathrm{L}$ was analyzed by gas chromatography to calculate the conversion rate of phytosterol (Equation 1) [8]. Each sample was tested three times.

$$
\text { Con. Rate }(\%)=\frac{B}{B+1.63 A} \times 100
$$

(1)

In the equation, $A$ : peak area sum of sterol $(\beta-$ sitosterol + brassicasterol + campesterol + stigmasterol); B: peak area sum of sterol ester; 1.63: the ratio of the average molecular weight of the sterol ester to the average molecular weight of the sterol.

Gas chromatographic conditions: The capillary column model was Agilent DB-5 HT at a size of $15.0 \mathrm{~m}$ $\times 320 \mu \mathrm{m} \times 0.10 \mu \mathrm{m}$. Gas flow rate was $3.5 \mathrm{~mL} / \mathrm{min}$. The temperature of the sample injector was $320^{\circ} \mathrm{C}$. The temperature of the flame ionization detector was $350^{\circ} \mathrm{C}$. The temperature of the chromatographic column started at $210{ }^{\circ} \mathrm{C}$ for $2 \mathrm{~min}$ and was heated up to $320^{\circ} \mathrm{C}$ at the speed of $10^{\circ} \mathrm{C} / \mathrm{min}$ and maintained for $15 \mathrm{~min}$. Then the temperature was heated up to $350{ }^{\circ} \mathrm{C}$ at the speed of 10 ${ }^{\circ} \mathrm{C} / \mathrm{min}$.

\subsubsection{Synthesis process optimization of $\beta$-sitosterol linolenate}

The effects of the temperature of reaction conditions (20 ${ }^{\circ} \mathrm{C}, 25^{\circ} \mathrm{C}, 30^{\circ} \mathrm{C}, 35^{\circ} \mathrm{C}, 40{ }^{\circ} \mathrm{C}$, and $50^{\circ} \mathrm{C}$ ), the amount of enzyme ( $3 \mathrm{U}, 9 \mathrm{U}, 12 \mathrm{U}, 15 \mathrm{U}, 18 \mathrm{U}$, and $24 \mathrm{U}$ ), the concentration of linolenic acid $(10 \mathrm{mmol} / \mathrm{L}, 20 \mathrm{mmol} / \mathrm{L}$, $30 \mathrm{mmol} / \mathrm{L}, 40 \mathrm{mmol} / \mathrm{L}, 50 \mathrm{mmol} / \mathrm{L}$, and $60 \mathrm{mmol} / \mathrm{L}$ ) and reaction time (120 $\mathrm{min}, 180 \mathrm{~min}, 240 \mathrm{~min}, 300 \mathrm{~min}$, $360 \mathrm{~min}, 480 \mathrm{~min}$ ) on the conversion rate of phytosterol were studied by single factor experiments (experimental methods in 2.3.1 and 2.3.2). Based on the optimal value of the single factor experiment, the central composite design (CCD) of response surface methodology (RSM) was used to design experiments with the software Design-expert 8.0.6, and factors and levels were selected. The interaction between factors was analyzed, and the optimal reaction conditions for phytosterol ester synthesis were determined. The accuracy of the results was verified through experiments.

\subsubsection{Reusability determination of CRL@PE}

After each round of $\beta$-sitosterol linolenate synthesis reaction, the pressure bottle was allowed to stand. After the solution was layered, $95 \%$ isooctane was carefully removed from CRL@PE, and then the same amount of new isooctane was used to wash the remaining substances several times until the phytosterol or phytosterol ester was removed (no substrate and product signal in the gas chromatograph). Then new isooctane, phytosterol and linolenic acid (the amount was equal to that in the first round of reaction) were added to start the next round of reaction. After the reaction was completed, the conversion rate of phytosterol was analyzed and calculated by gas chromatography.

\section{Results and discussion}

\subsection{Single factor optimization of synthesis conditions of $\beta$-sitosterol linolenate}

\subsubsection{Effect of temperature on phytosterol conversion rate}

The effect of temperature on phytosterol conversion rate was shown in Fig. 1a, and the overall trend was a shape of "up-flat-down". As the temperature increased, the conversion rate gradually increased. The maximum value reached $72.5 \%$ at $30{ }^{\circ} \mathrm{C}$. As the temperature continued to increase, the conversion rate began to decrease. The higher the temperature, the faster the drop became. Low temperature or high temperature inhibited the catalytic performance of the enzyme, resulting in a decrease in the reaction speed. High temperature caused the zymoprotein degeneration, and lipase was inactivated due to structural change. Therefore, $30^{\circ} \mathrm{C}$ was chosen as the reaction temperature for the subsequent experiments.

\subsubsection{Effect of Enzyme dosage on phytosterol conversion rate}


As showed in Fig. 1b, phytosterol conversion rate increases rapidly with the increase of the amount of enzyme (6-15 U). However, the continued increase in the amount of enzyme $(>15 \mathrm{U})$ results in a decrease in the conversion rate. In CRL@PE, a large amount of lipase might accumulate at the biphasic interface. The limited interfacial area of each liquid drop leaded to the inhibition of substrate diffusion, and the reaction speed was slowed down due to insufficient substrate. Lipase might also accumulate in the core of the aqueous phase, and it was difficult to exert the effect because lipase did not contact with the substrate. In summary, the amount of enzyme of $12 \mathrm{U}$ was selected as the catalyst amount for the subsequent reactions.

\subsubsection{Effect of linolenic acid concentration on phytosterol conversion rate}

The effect of linolenic acid concentration on phytosterol conversion rate was shown in Fig. 1c. With the increase of linolenic acid concentration, the conversion rate showed a fast growth trend. When linolenic acid concentration exceeded $40 \mathrm{mmol} / \mathrm{L}$, the trend slowed down, indicating that the reaction reached an equilibrium point after $240 \mathrm{~min}$ of reaction and that the conversion rate reached the maximum value. Considering the production cost and reaction efficiency, the amount of linolenic acid of $40 \mathrm{mmol} / \mathrm{L}$ was selected for subsequent reactions.

\subsubsection{Effect of reaction time on phytosterol conversion rate}

Fig. 1d shows the process curve of the synthesis of $\beta$ sitosterol linolenate. As the reaction time progressed, the conversion rate of phytosterol gradually increased and remained basically unchanged after reaching the maximum value, which proved that the reaction reached an equilibrium point. Considering the cost, 300 min was chosen as the optimal reaction condition.

\subsection{Response surface optimization of synthesis conditions of $\beta$-sitosterol linolenate}

According to the single factor optimization results, RSM-CCD research approach was developed. Temperature $\left(22-38{ }^{\circ} \mathrm{C}\right)$, Enzyme dosage (6-18 U), linolenic acid concentration $(12-68 \mathrm{mmol} / \mathrm{L})$, and time (60-540 min) were determined as independent variables, and the phytosterol conversion rate was determined as response variable. Factors and levels were screened by using the software Design-Expert 8.0.6 (Table 1), and 28 experiments were designed (Table 2), where the conversion rate of sterol was a minimum of $51.20 \%$ and a maximum of $95.80 \%$. The $3 \mathrm{D}$ response surface was used to further study the effects of various factors and levels on the conversion rate of sterol and to construct a polynomial equation to analyze and predict experimental results (Equation 2):
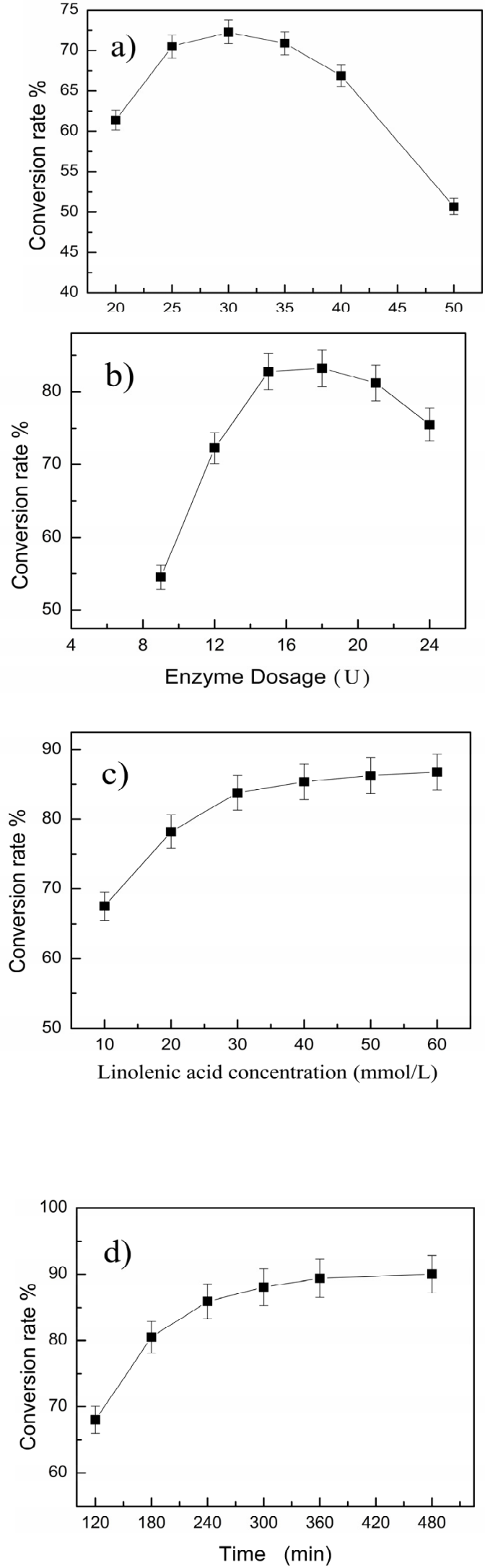

Fig. 1 Single factor experiment of phytosterol linolenic ester synthesis a) Temperature ( $9 \mathrm{U}, 30 \mathrm{mmol} / \mathrm{L}$, and $240 \mathrm{~min}) ; \mathrm{b}$ ) Enzyme dosage $\left(30^{\circ} \mathrm{C}, 30 \mathrm{mmol} / \mathrm{L}\right.$, and $\left.240 \mathrm{~min}\right)$; c) Linolenic acid concentration $\left(30^{\circ} \mathrm{C}, 12 \mathrm{U}\right.$, and $\left.240 \mathrm{~min}\right)$; d ) Time $\left(30^{\circ} \mathrm{C}\right.$, $12 \mathrm{U}$, and $40 \mathrm{mmol} / \mathrm{L}$ ) 
Table 1. Response surface experimental factors and levels

\begin{tabular}{lllllll}
\hline Symbols & Independent variables & levels & & & \\
& & -2 & -1 & 0 & +1 & +2 \\
\hline $\mathrm{A}$ & Temperature $\left({ }^{\circ} \mathrm{C}\right)$ & 22 & 26 & 30 & 34 & 38 \\
$\mathrm{~B}$ & Enzyme dosage $(\mathrm{U})$ & 6 & 9 & 12 & 15 & 18 \\
$\mathrm{C}$ & Linolenic acid concentration & 12 & 26 & 40 & 54 & 68 \\
$\mathrm{D}$ & $(\mathrm{mmol} / \mathrm{L})$ & 60 & 180 & 250 & 420 & 540 \\
\hline
\end{tabular}

Table 2. Response surface experimental scheme and results

\begin{tabular}{llllll}
\hline No. & $\begin{array}{l}\text { A: } \\
\text { Temperature } \\
\left({ }^{\circ} \mathrm{C}\right)\end{array}$ & $\begin{array}{l}\text { B: Enzyme dosage } \\
(\mathrm{U})\end{array}$ & $\begin{array}{l}\text { C: Linolenic acid } \\
\text { concentration }(\mathrm{mmol} / \mathrm{L})\end{array}$ & $\begin{array}{l}\text { D: Time } \\
(\mathrm{min})\end{array}$ & Conversion \% \\
\hline 1 & 26 & 9 & 26 & 180 & 53.01 \\
2 & 34 & 9 & 26 & 180 & 55.20 \\
3 & 26 & 15 & 26 & 180 & 65.64 \\
4 & 34 & 15 & 26 & 180 & 70.37 \\
5 & 26 & 9 & 54 & 180 & 71.72 \\
6 & 34 & 9 & 54 & 180 & 72.49 \\
7 & 26 & 15 & 54 & 180 & 80.00 \\
8 & 34 & 15 & 54 & 180 & 82.59 \\
9 & 26 & 9 & 26 & 420 & 83.05 \\
10 & 34 & 9 & 26 & 420 & 78.27 \\
11 & 26 & 15 & 26 & 420 & 91.00 \\
12 & 34 & 15 & 26 & 420 & 88.27 \\
13 & 26 & 9 & 54 & 420 & 92.00 \\
14 & 34 & 9 & 54 & 420 & 87.28 \\
15 & 26 & 15 & 54 & 420 & 95.80 \\
16 & 34 & 15 & 54 & 420 & 92.50 \\
17 & 22 & 12 & 40 & 300 & 75.90 \\
18 & 38 & 12 & 40 & 300 & 75.16 \\
19 & 30 & 6 & 40 & 300 & 75.16 \\
20 & 30 & 18 & 40 & 300 & 94.50 \\
21 & 30 & 12 & 12 & 300 & 71.64 \\
22 & 30 & 12 & 40 & 300 & 94.55 \\
23 & 30 & 12 & 40 & 60 & 51.20 \\
24 & 30 & 12 & 540 & 91.25 \\
$25-28$ & 30 & & 300 & 95.58 \\
\hline
\end{tabular}

Table 3. Analysis of variance table

\begin{tabular}{llll}
\hline Term & F-value & P-value (Prob $>$ F) & Value \\
\hline Model & 2142.85 & $<0.0001$ & \\
A:Temperature & 11.33 & $<0.0001$ & \\
B: Enzyme dosage & 3128.45 & $<0.0001$ & \\
C: Linolenic acid concentration & 4585.49 & $<0.0001$ & \\
D: Time & 14080.72 & $<0.0001$ & \\
AB & 23.01 & 0.0003 & \\
AC & 6.22 & 0.0269 & \\
$\mathrm{AD}$ & 249.97 & $<0.0001$ & \\
$\mathrm{BC}$ & 126.35 & $<0.0001$ & \\
$\mathrm{BD}$ & 138.47 & $<0.0001$ & \\
$\mathrm{CD}$ & 475.29 & $<0.0001$ & \\
$\mathrm{~A}^{2}$ & 3523.59 & $<0.0001$ & \\
$\mathrm{~B}^{2}$ & 989.17 & $<0.0001$ & \\
$\mathrm{C}^{2}$ & 1343.79 & $<0.0001$ & \\
$\mathrm{D}^{2}$ & 5224.24 & $<0.0001$ & \\
Lack of Fit & 0.72 & 0.6992 & 0.9996 \\
$\mathrm{R}^{2}$ & & & 0.9991 \\
AdjustedAdj-R & & & 0.9980 \\
Predicted $\mathrm{R}^{2}$ & & & 148.935 \\
Adeq-Precision & & & 0.50 \\
Coefficient of variation \% & & & \\
\hline
\end{tabular}


Con. Rate (\%) $=88.05-1.54 A+9.90 B+6.79 C+11.09 D$

$+0.98 A B-0.51 A C-3.23 A D-1.15 B C-1.20 B D$

$-2.22 C D-19.78 A^{2}-2.62 B^{2}-3.05 C^{2}-6.02 D^{2}$

RSM-CCD experimental results were analyzed, and the model equation was constructed. "Prob $>F$ " $<0.0001$ indicates that the model project was significant. Similarly, the $\mathrm{P}$ values of temperature, enzyme dosage, linolenic acid concentration and time were less than 0.05 , indicating significant effects on the conversion rate. The missing term was greater than 0.05 indicating that there was no significant effect. The equation could be used for data analysis and result prediction. The corrected coefficient of determination (0.9991) indicated that $99.91 \%$ of the yield variation was distributed among the factors of the equation, and only $0.9 \%$ could not be explained by the model. The correlation coefficient $\mathrm{R}^{2}$ was 0.9996 , indicating that there was a good degree of fitting between the measured value and the predicted value of the yield. In combination, this model can be used to predict the actual yield of natamycin. AdeqPrecision was the ratio of detected noise signals, and its value greater than 4 indicated that the model could truly reflect the experimental results [9]. The coefficient of variation showed the accuracy of the experiment, and the value of $0.5 \%$ indicated that the experimental operation was reliable.

In Fig. 2, the interaction between two factors and their effects on conversion rate of phytosterol during the synthesis of $\beta$-sitosterol linolenate were analyzed (other factors were at intermediate levels). Fig. 2a shows the effects of temperature and enzyme dosage on conversion rate when linolenic acid concentration and time are at intermediate levels. The umbrella-shaped surface indicates that temperature and enzyme dosage have significant effects on the conversion rate. As the amount of enzyme increased, the conversion rate increased at a constant temperature. When the amount of enzyme was fixed, the temperature deviated from the central value, which could lead to a decrease in the conversion rate.

This could be explained by the fact that under certain conditions, the enzyme could effectively increase the conversion rate of phytosterol, and the more the amount, the more significant the effect. However, high temperature or low temperature could inhibit the catalytic ability of the enzyme and even cause the enzyme to be inactivated. Fig. $2 b$ shows the effects of temperature and linolenic acid concentration on conversion rate. The conversion rate reached a maximum when the temperature was at " 0 " level and the linolenic acid concentration was near the " +1 " level. In Fig. 2c, as the amount of enzyme or time increased, the conversion rate of phytosterol also increased. The growth trend gradually slowed down, so the maximum conversion rate existed in the range of high levels.

According to the analysis of RSM-CCD results, optimal synthesis conditions of $\beta$-sitosterol linolenate were temperature at $29.45^{\circ} \mathrm{C}$, enzyme dosage of $10.97 \mathrm{U}$, linolenic acid concentration of $42.35 \mathrm{mmol} / \mathrm{L}$, and reaction time of $350.7 \mathrm{~min}$. The polynomial predicted conversion rate was $97.5 \%$ under the optimal conditions.
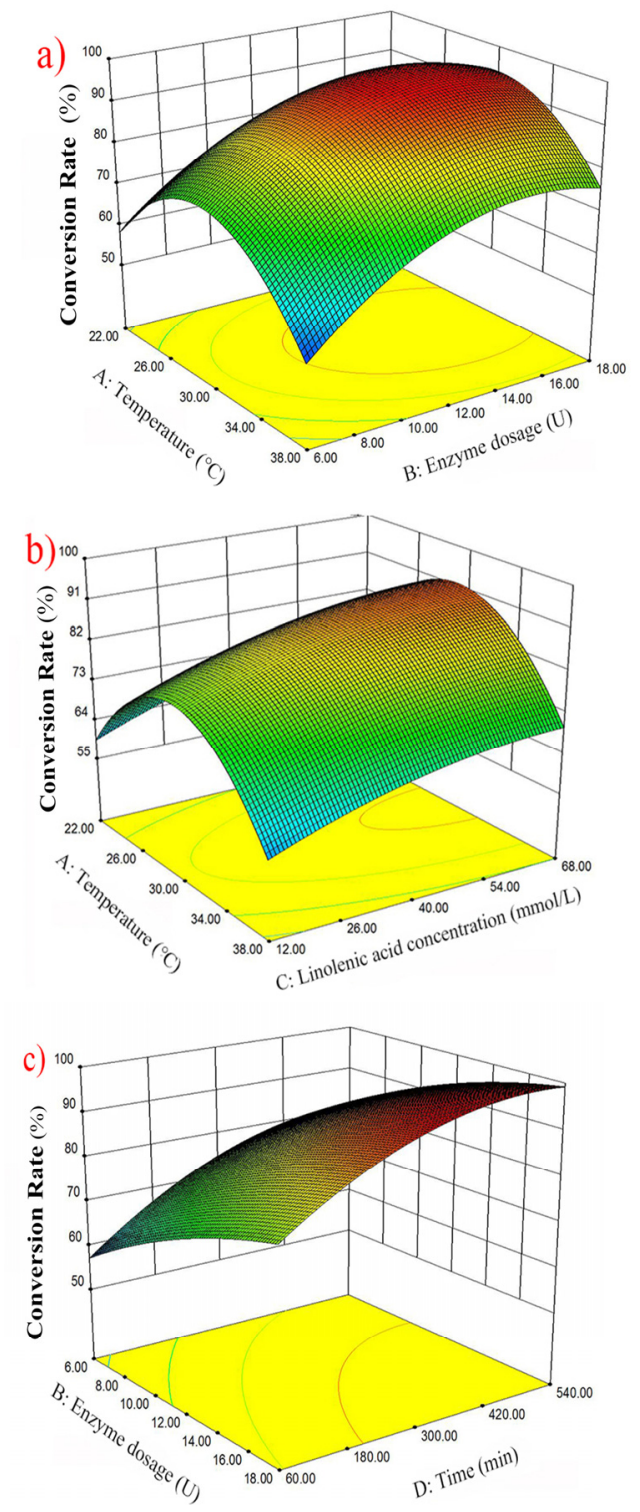

Fig. 2 Response surface plots showing effect of two parameters on phytosterol conversion rate (a) Temperature vs. Enzyme dosage; (b) Temperature vs. Linolenic acid concentration; (c) Enzyme dosage vs. Time

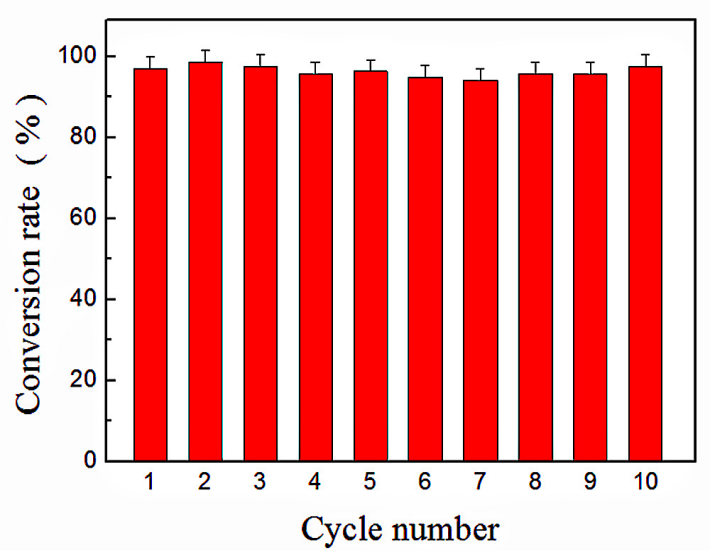

Fig. 3 The reusability of CRL@PE 
The actual conversion rate of phytosterol was $97.2 \pm 0.7 \%$ by the verification of three experiments (29.5 ${ }^{\circ} \mathrm{C}, 11 \mathrm{U}, 42.4 \mathrm{mmol} / \mathrm{L}$, and $350.7 \mathrm{~min}$ ).

\subsection{Reusability of CRL@PE}

Reusability is an important parameter for the evaluation of the application value of catalyst. Fig. 3 shows the reusability of CRL@PE in the synthesis of sitosterol linolenate. When CRL@PE was used as the catalyst for the first time, the conversion rate of phytosterol was $97.11 \%$. After repeated use for 10 times, the conversion rate was still $96.86 \%$, which remained unchanged. Therefore, CRL@PE had good reusability.

\section{Conclusion}

In this experiment, a novel two-phase catalyst of Pickering emulsion was constructed with isooctane and enzyme-containing solution by using nanotubes as emulsifiers. It was used for the first time to catalyze and synthesize $\beta$-sitosterol linolenate. The effects of temperature, enzyme dosage, linolenic acid concentration and reaction time on the conversion rate of phytosterol were studied by single factor experiments and the central composite design of response surface methodology. The optimal reaction conditions were as follows: temperature at $29.45{ }^{\circ} \mathrm{C}$, enzyme dosage of $10.97 \mathrm{U}$, the linolenic acid concentration of 42.35 $\mathrm{mmol} / \mathrm{L}$, and the reaction time of $350.7 \mathrm{~min}$. The maximum conversion rate of phytosterol was $96.8 \pm 0.7 \%$ under the optimal conditions. The next phase will examine the catalytic properties and stability of CRL@PE in detail, including catalytic kinetics, inactivation kinetics, and thermal stability, reusability, and storage stability. In the next stage, we will examine in detail the catalytic property and stability of CRL@PE, including catalytic kinetics, and inactivation kinetics, as well as thermostability, reusability, and storage stability.

\section{Acknowledgments:}

This work was supported by the Tianjin Jinnan District Science and Technology Project (Grant number: 20161515).

\section{References}

1. O. Weingärtner, I. Bogeski, Kummol/Lerow C, et al. Plant sterol ester diet supplementation increases serum plant sterols and markers of cholesterol synthesis, but has no effect on total cholesterol levels. J. Steroid Biochem. Mol. Biol. 169, 219 (2017)

2. T. Miettinen, P. Puska, H. Gylling, et al. Reduction of serum cholesterol with sitostanol-ester margarine in a mildly hypercholesterolemic population. N. Engl. J. Med. 333, 1308 (1995)

3. M. Molina-Gutiérrez, N.L.S. Hakalin, L. RodríguezSanchez, et al. Green synthesis of $\beta$-sitostanol esters catalyzed by the versatile lipase/sterol esterase from Ophiostoma piceae. Food Chem. 221, 1458 (2017)

4. M. Miao, H. Liu, B. Jiang, et al. Enzyme-catalysed synthesis of plant steryl laurate in non-aqueous media using salt hydrate pairs and its characterisation. J. Funct. Foods 7, 452 (2014)

5. M.M. Zheng, Y. Lu, L. Dong, et al. Immobilization of Candida rugosa lipase on hydrophobic/strong cation-exchange functional silica particles for biocatalytic synthesis of phytosterol esters. Bioresour. Technol. 115, 141 (2012)

6. C. Wu, S. Bai, M. Ansorge-Schumacher, et al. Nanoparticle Cages for Enzyme Catalysis in Organic Media. Adv. Mater. 23, 5694 (2011)

7. Y.J. Jiang, X.L. Liu, Y.F. Chen, et al. Pickering emulsion stabilized by lipase-containing periodic mesoporous organosilica particles: A robust biocatalyst system for biodiesel production. Bioresour. Technol. 153, 278 (2014)

8. D. Kumar, S. Nagar, I. Bhushan, et al. Covalent immobilization of organic solvent tolerant lipase on aluminum oxide pellets and its potential application in esterification reaction. J. Mol. Catal. B: Enzym. 87, 51 (2013)

9. L. Liu, Y. Hong, X. Ye, et al. Biodiesel production from microbial granules in sequencing batch reactor. Bioresour. Technol. 249, 908 (2018) 